\title{
Developmental Communalities in Tooth Emergence Timing
}

\author{
STANLEY M. GARN and B. HOLLY SMITH
}

Center for Human Growth \& Development, The University of Michigan, Ann Arbor, Michigan 48109

\section{J Dent Res 59(7):1178, July 1980}

Intercorrelations and communalities are now well known for tooth formation (Garn et al., J Dent Res 39:1049, 1960), crown size of the permanent teeth (Moorees and Reed, Arch Oral Biol 9:685, 1964; Garn et al., J Dent Res 44:350, 1965), the deciduous teeth (Garn et al., J Dent Res 56:1214, 1977), and crown size of deciduous teeth during odontogenesis (Garn et al., J Dent Res 58:554, 1979). However, comparable analytic information has not been presented for postnatal tooth emergence timing of 11 through $\mathrm{M} 2$.

To explore these emergence relationships and their relative magnitudes, tooth emergence (timing) correlations were calculated using coded emergence data derived from serial casts of 204 participants in the Longitudinal Study of the University of Michigan (Moyers et al., Standards of Human Occlusal Development, Ann Arbor: The Center for Human Growth and Development, 1976). Individual ages of tooth emergence were $Z$-scored for males and females separately for each of 28 permanent teeth, and the entire matrix of 121 pooled-sex tooth-pair intercorrelations was then computer correlated. Correlation coefficients for intra-quadrant pairs, antimeres, isomeres, and teeth separated by numbers of intervening teeth were separately averaged using the $z$ transform of $r$.

As snown in the Table, where correlations are

Received for publication November 5, 1979

Accepted for publication December 6, 1979 Garn. grouped for antimeres, isomeres, and distance, the relative magnitudes of the correlations follow a systematic hierarchy. Antimeres show the highest mean $r(0.88)$, despite their position on opposite sides of the arch. The next highest values of $r$ are found for isomeres or opponents $(0.74)$, followed in turn by the mean $r$ for adjacent teeth $(0.70)$. It is seen that adjacent teeth of the same morphological class show only a minimally higher $r(0.71)$ than adjacent teeth of different classes (mean $r$ of 0.69 ). Clearly, the high values of $r$ found for teeth of the same morphological class can be accounted for by proximity rather than morphological class. Finally, arranging the tooth emergence correlations according to number of intervening teeth (distance), the values of mean $r$ are $0.70,0.63,0.54$, and 0.50 for $0,1,2$, and 3 intervening teeth, respectively. Without question, tooth emergence timing shows a distance effect with a clear-cut decreasing gradient.

It is impressive that both magnitudes of the tooth emergence correlations and the patterns of correlations strongly resemble communalities for odontogenesis, crown calcification, and buccolingual crown dimensions. Adjacent teeth (such as $\mathrm{M} 1$ and $\mathrm{M} 2$ ) are closely correlated in emergence, even though actual emergence timing may be six years apart. The distance gradient, decreasing with the number of intervening teeth, similarly transcends emergence orders. Though local and systemic factors that control emergence must differ both quantitatively and qualitatively from factors that determine odontogenesis, tooth formation, or crown size, ultimate control mechanisms must be much the same. The dentition, therefore, emerges as a remarkably integrated system in all of its measurable aspects.

TABLE

EMERGENCE COMMUNALITIES FOR ISOMERES, ANTIMERES, ADJACENT TEETH, AND DISTANCE

\begin{tabular}{|c|c|c|c|c|c|c|c|}
\hline \multirow{2}{*}{$\begin{array}{l}\text { Morphologic } \\
\text { Relationship }\end{array}$} & \multirow[b]{2}{*}{ No. } & \multicolumn{2}{|c|}{ Correlations* } & \multirow{2}{*}{$\begin{array}{c}\text { Distance } \\
\text { Relationship }\end{array}$} & \multicolumn{3}{|c|}{ Correlations* } \\
\hline & & Mean & S.E. & & No. & Mean & S.E. \\
\hline All antimeres & 14 & 0.88 & .02 & adjacent & 24 & 0.70 & .02 \\
\hline All isomeres & 14 & 0.74 & .02 & 1 intervening & 20 & 0.63 & .02 \\
\hline All adjacent intraclass & 12 & 0.71 & .02 & 2 intervening & 16 & 0.54 & .02 \\
\hline All adjacent interclass & 12 & 0.69 & .03 & 3 intervening & 12 & 0.50 & .03 \\
\hline
\end{tabular}

*From the mean $z$ transform of $r$ for the number or correlations shown, using sex-specific Z-scores for emergence age; rounding off the standard errors. 